\title{
Management of Human and Animal Bite Wound Infection: An Overview
}

\author{
Itzhak Brook, MD, MSc
}

\author{
Corresponding author \\ Itzhak Brook, MD, MSc \\ Department of Pediatrics, Georgetown University School of \\ Medicine, 4431 Albemarle Street NW, Washington DC 20016, USA. \\ E-mail: ib6@georgetown.edu \\ Current Infectious Disease Reports 2009, 11:389-395 \\ Current Medicine Group LLC ISSN 1523-3847 \\ Copyright (C) 2009 by Current Medicine Group LLC
}

Animal and human bite wounds can lead to serious infections. The organisms recovered generally originate from the biter's oral cavity and the victim's skin flora. Anaerobes were isolated from more than two thirds of human and animal bite infections. Streptococcus pyogenes is often recovered in human bites, Pasteurella multocida in animal bites, Eikenella corrodens in animal and human, Capnocytophaga spp, Neisseria weaveri, Weeksella zoohelcum, Neisseria canis, Staphylococcus intermedius, nonoxidizer-1, and eugonic oxidizer-2 in dog, Flavobacterium group in pig, and Actinobacillus spp in horse and sheep bites. Vibrio spp, Plesiomonas shigelloides, Aeromonas hydrophila, and Pseudomonas spp can cause infections in bites associated with marine settings. In addition to local wound infection, complications include lymphangitis, local abscess, septic arthritis, tenosynovitis, and osteomyelitis. Uncommon complications include endocarditis, meningitis, brain abscess, and sepsis with disseminated intravascular coagulation especially in immunocompromised individuals. Wound management includes administering local care and using proper antimicrobial therapy when needed.

\section{Introduction}

Animal and human bites and other orally contaminated wounds are common, with more than 1 million animal bites occurring annually in the United States $[1-3,4 \bullet \bullet]$ Bite wounds typically contain polymicrobial flora that generally reflect the aerobic and anaerobic microbiology of the oral flora of the biter, the skin of the victim, and the environment. Bite wounds include scratches, punctures, lacerations, and evulsions. Often these wounds can appear innocuous initially, but frequently lead to serious infection and complications [5]. This review presents the microbiology and management of animal and human bite infections.

\section{Microbiology}

The organisms that can be recovered from bite wounds generally originate from the oral cavity of the biting animal and from the victim's own skin flora. Most infections are polymicrobial and synergistic. In studies that used adequate methods to recover aerobic and anaerobic bacteria, anaerobes were isolated from more than two thirds of human and animal bite wound infections, especially those associated with abscess formation [6-9]. Streptococcus pyogenes is generally found in human bites, Pasteurella multocida in animal bites [10], Eikenella corrodens in both animal and human bites (mostly with the latter), Capnocytophaga canimorsus (formerly Centers for Disease Control and Prevention [CDC] group DF-2) [11], Capnocytophaga cynodegmi, Neisseria weaveri (formerly CDC group M-5) [10], Weeksella zoohelcum (formerly II-J) [11], Neisseria canis [12], Staphylococcus intermedius [13], nonoxidizer-1 [14], and eugonic oxidizer-2 [15] in dog bites, a Flavobacterium group IIb-like organism in an infected pig bite [16], and Actinobacillus spp in horse and sheep bites [17]. Vibrio spp, Plesiomonas shigelloides, Aeromonas hydrophila, and Pseudomonas spp have caused infections in bites occurring in marine settings [18].

Serious systemic infections can be transmitted through bites: tularemia from cats [19], herpes B virus from monkeys, rat-bite fever and sodoku from rats, hepatitis B virus from humans, leptospirosis from dogs and rodents, and rabies from dogs and other mammals.

\section{Human bites}

Staphylococcus aureus was the organism most frequently isolated in studies that did not use anaerobic methodology [20]. Penicillin-resistant gram-negative rods alone or in mixed culture were reported in $24 \%$ to $43 \%$ of bite wounds cultured [21].

Studies that used anaerobic methodologies reported the recovery of anaerobic bacteria in human bites in adults [21] and children [22]. Goldstein et al. [21] recovered anaerobic bacteria in more than half of human bite wounds and clenched-fist injuries. The predominant isolates were anaerobic gram-negative bacilli (including pigmented Prevotella and Porphyromonas spp, and Bacteroides spp), Fusobacterium nucleatum, and anaerobic gram-positive cocci. The predominant aerobes recovered 


\begin{tabular}{|c|c|c|}
\hline Isolates & Animal & Ian bite \\
\hline \multicolumn{3}{|l|}{ Aerobic and facultative } \\
\hline \multicolumn{3}{|l|}{ Streptococcus spp } \\
\hline$\alpha$-Hemolytic & + & + \\
\hline Group A $\beta$-hemolytic & + & + \\
\hline Non-group A $\beta$-hemolytic & + & + \\
\hline$\gamma$-Hemolytic & + & + \\
\hline Enterococcus spp & + & + \\
\hline Staphylococcus aureus & + & + \\
\hline Staphylococcus epidermidis & + & + \\
\hline Neisseria spp & + & + \\
\hline Corynebacterium spp & + & + \\
\hline Pasteurella multocida & + & - \\
\hline Eikenella corrodens & + & + \\
\hline Acinetobacter spp & + & - \\
\hline Weeksella zoohelcum & + & - \\
\hline Haemophilus spp & + & + \\
\hline Moraxella spp & + & - \\
\hline Capnocytophaga spp & + & - \\
\hline \multicolumn{3}{|l|}{ Anaerobic } \\
\hline Peptostreptococcus spp & + & + \\
\hline Veillonella spp & + & + \\
\hline Bifidobacterium spp & - & + \\
\hline Eubacterium spp & - & + \\
\hline Fusobacterium spp & + & + \\
\hline Bacteroides spp & + & + \\
\hline Prevotella spp & + & + \\
\hline Fusobacterium spp & + & + \\
\hline
\end{tabular}

were $S$. aureus, group A $\beta$-hemolytic streptococci, and E. corrodens.

Talan et al. [2] conducted a multicenter, prospective study of 50 patients with infected human bites. Fifty-six percent of injuries were clenched-fist injuries and $44 \%$ were occlusional bites. The median number of isolates per wound culture was four (three aerobes and one anaerobe); aerobes and anaerobes were isolated from $54 \%$ of wounds, aerobes alone were isolated from $44 \%$, and anaerobes alone were isolated from $2 \%$. Isolates included Streptococcus anginosus (52\%), S. aureus (30\%), E. corrodens (30\%), F. nucleatum (32\%), and Prevotella melaninogenica (22\%). Candida spp were found in $8 \%$ of wounds. Fusobacterium, Peptostreptococcus, and Candida spp were isolated more frequently from occlusional bites than from clenched-fist injuries. Many strains of Prevotella and S. aureus were $\beta$-lactamase producers.
Brook [22] recovered anaerobes in $90 \%$ of 18 children with human bites (Table 1). A total of 97 isolates (range, 1 to 8 per specimen) were recovered (5.4 per specimen): 44 aerobes (2.4 per specimen) and 53 anaerobes $(3.0$ per specimen). $\beta$-Lactamase activity was noted in 13 isolates that were recovered from 11 patients. These included all 9 isolates of $S$. aureus, 2 of the 6 pigmented Prevotella and Porphyromonas spp, 1 of 3 Prevotella oralis, and the single isolate of Bacteroides ovatus. The results of these studies show that normal oral flora, rather than skin flora, is the source of most bacteria isolated from human bite wound cultures.

\section{Animal bites}

Almost any aerobic or anaerobic oral flora isolate is a potential pathogen, and therefore the bacteriology of bite wounds is variable and needs individual study [23,24].

Holst et al. [10] investigated the distribution of 159 P. multocida isolates from bite wounds. P. multocida accounted for $60 \%$ of the isolates and was recovered in all cases of bacteremia. Pasteurella septica accounted for $13 \%$ of isolates, was more commonly isolated from cat than from dog bites, and caused more central nervous system complications. Pasteurella canis (biotype 1) was recovered from $18 \%$ of wounds-all dog bites. Isolates less often recovered include Pasteurella stomatis, Pasteurella dagmatis, Pasteurella gallinarum, Pasteurella haemolytica, and Pasteurella pneumotropica, which have also been associated with endocarditis and bacteremia.

In addition to Pasteurella spp, anaerobic bacteria play a prominent role in bite wound infections [6-9,23]. They can be isolated from about three quarters of dog and cat bite wound infections, mostly from those where an abscess formed [6-9,23]. Anaerobic gram-negative bacilli are the predominant anaerobic isolates. The most frequently isolated strains include Porphyromonas salivosa, Porphyromonas gingivalis, and Porphyromonas canoris. Other isolates include Porphyromonas cangingivalis, Porphyromonas cansulci, Porphyromonas circumdentaria, Porphyromonas levii-like strains, and some unidentified species [9]. Saccharolytic Bacteroides and Prevotella spp are also often recovered from dog and cat bite wounds. These include Bacteroides tectum, Prevotella heparinolytica, Prevotella zoogleoformans, Prevotella buccae, and Prevotella oris [8].

Using aerobic and anaerobic cultural methods, Goldstein et al. [23] evaluated 27 dog bite wounds and isolated 109 organisms-87 aerobes and 22 anaerobes. All positive cultures yielded multiple organisms; most were potential pathogens. $P$. multocida was recovered from 7 of 27 wounds $(30 \%)$, and the most common aerobes were the $\alpha$-hemolytic streptococci and $S$. aureus. Anaerobes were present in $41 \%$ of wounds, especially gram-negative bacilli (pigmented Prevotella and Porphyromonas spp) and Fusobacterium spp. Similar data were found regarding other animal bites (cats, squirrels, other rodents, and rattlesnakes) [10]. 
Brook [22] evaluated 21 children who had animal bites-17 from dogs and 4 from cats. Aerobes only were isolated in 5 children (24\%), anaerobic bacteria only in $2(10 \%)$, and mixed aerobic and anaerobic isolates in $14(66 \%)$. A total of 59 isolates (2.8 per specimen) were recovered: 37 aerobes (1.8 per specimen) and 22 anaerobes (1.0 per specimen).

Talan et al. [24] studied wounds of 50 patients with dog bites and 57 patients with cat bites. They recovered a median of five isolates per culture. Aerobes and anaerobes were found in $56 \%$ of the wounds, aerobes alone in $36 \%$, and anaerobes alone in $1 \%$. Pasteurella spp were the most common isolates from both dog and cat bites. Other aerobes included streptococci, staphylococci, Moraxella spp, and Neisseria spp. Anaerobes included Fusobacterium spp, Bacteroides spp, Porphyromonas spp, and Prevotella spp. Isolates not previously identified as human pathogens included Reimerella anatipestifer from two cat bites and B. tectum, P. heparinolytica, and several Porphyromonas spp from dog and cat bites. Erysipelothrix rhusiopathiae was isolated from two cat bites.

The microbiology of monkey and simian bite wounds is similar to human bites, in which aerobic and anaerobic pathogens are the infecting agents. These include Streptococcus spp, Enterococcus spp, and Staphylococcusspp, E.corrodens, NeisseriasppEnterobacteriaceae, and anaerobes such as gram-negative bacilli and Fusobacterium spp.

B virus (also known as Herpes-virus simiae; Cercopithecine herpes virus 1 ) is a potential pathogen with some monkey bites [25]. This infection can cause fatal encephalomyelitis. It is enzootic in monkeys of North Africa and Asia, and affects the macaque and rhesus monkeys.

The organisms recovered from horse bite wounds include S. aureus, Streptococcus spp, Neisseria spp, Escherichia coli, Actinobacillus lignieresii, Pasteurella spp, Bacteroides ureolyticus, Bacteroides fragilis, other anaerobic gram-negative bacilli, Prevotella melaninogenica, and $P$. heparinolytica $[26,27]$. Actinobacillus organisms are associated with sheep bites [26].

The organisms recovered from pig bite infections are Staphylococcus spp, Streptococcus spp (including Streptococcus sanguis, Streptococcus suis, and Streptococcus milleri), diphtheroids, P. multocida, other Pasteurella spp, Haemophilus influenzae, Actinobacillus suis, Flavobacterium IIb-like organisms, $B$. fragilis, and other anaerobic gram-negative bacilli $[16,27-30]$.

Organisms from marine environments cause aquatic animal bite infections [31-37]. These infections often involve Vibrio and Aeromonas spp, which can also be recovered from the oral cavity of the shark [31-33]. Vibrio carchariae was recovered from a shark bite infection [32]. Aeromonas hydrophila was recovered from a cellulitis that occurred after a piranha bite [35] and alligator bites [36]. Isolates from catfish bites and injuries were Vibrio spp (as Vibrio vulni ficus), Vibrio damsela, Pseudomonas spp, Enterobacteriaceae, A. hydrophila, and Peptostreptococcus spp [37].

Bird pecking and bites can induce serious infections. A brain abscess that was caused by Streptococcus bovis, Clostridium tertium, and Aspergillus niger developed in an infant after a rooster pecked his skull [38]. An owl attack resulted in superficial cellulitis caused by two nonfragilis Bacteroides spp [39], and a swan bite induced cellulitis from Pseudomonas aeruginosa [40].

Ferrets caused serious facial injuries in three infants, and $S$. aureus was isolated in one patient [41].

\section{Diagnosis}

The symptoms that emerge following a bite depend on the type of animal inflicting the insult. The immediate local or systemic symptoms can be severe following a bite from a venomous animal (eg, snake, lizard, spider). Human or dog bites generally do not cause immediate symptoms in addition to the laceration injury. However, because of the direct inoculation of oral and skin flora into the wound, an infection can develop rapidly, with signs and symptoms appearing in 24 to 72 hours. The signs of infection include redness, swelling, and clear or purulent discharge. The adjacent lymph nodes may be enlarged, and range of motion of an extremity can be reduced. Leukocytosis may occur, with 15,000 to 30,000 cells $/ \mathrm{mm}^{3}$. The observation of an eschariform lesion in a sick-appearing individual may suggest the presence of C. canimorsus infection [42].

Human bites generally are more serious than animal bites. This is especially the case in a clenched-fist injury, when the skin over the knuckles is penetrated after striking the teeth of another person. The teeth can cause a deep laceration that implants oral and skin organisms into the joint capsules or dorsal tendons, thus causing septic arthritis or osteomyelitis. Radiographs of hands injured by teeth are recommended [43]. It is very important to determine the medical status of the source of the human bite (eg, infections with a hepatitis virus, HIV status, and other transmittable diseases).

About $2 \%$ to $5 \%$ of all typical dog bite wounds seen in emergency departments become infected $[4 \bullet \bullet]$. However, the rabies status of the dog should be ascertained in each instance. Wounds that completely penetrate the skin have an infection rate of $6 \%$ to $13 \%$, depending on location. In comparison, the infection rate of clean lacerations repaired in the emergency department is about $5 \%$ [44].

Gram stain and culture for aerobic and anaerobic bacteria should be obtained from human and animal bite wounds. Using culture and microbiologic methods that are adequate for the recovery of anaerobic bacteria are essential. If wounds are contaminated by soil or vegetative debris, culture for mycobacteria and fungi should also be performed. Determination of the sedimentation rate or C-reactive protein can help in cases of osteomyelitis and septic arthritis to determine the duration of antimicrobial therapy. 


\section{Management}

Management of wounds includes proper local care, and use of antimicrobial agent(s) when needed. The steps involved in evaluation and wound care for bites include recording the medical history (animal involved, provoked or unprovoked attack, current medications, splenectomy, mastectomy, allergies, chronic disease, and immunosuppression), examination of the wound and related structures (odor of exudates, depth, type, location, range of motion, joint involvement, edema or crush injury, nerve and tendon damage, presence of infection), obtaining wound cultures, irrigating the wound with saline, débridement, obtaining radiographs (when bone penetration is suspected), wound approximation, administering antimicrobials, tetanus and rabies immunization when indicated, herpes B virus evaluation (in monkey bites), and re-examination at 24 and 48 hours. The incident should be reported to the local health authorities when indicated.

Bites should be managed as any laceration: cleanse, explore, irrigate, débride, drain, and possibly suture. The wounds should be washed vigorously with soap or a quaternary ammonium compound and water. This is of primary importance in reducing the high inoculum of the oral flora of the biting human or animal. The physician should explore for tissue damage caused by crushing or tearing and should search for damaged tendons, blood vessels, joints, and bones. X-ray examination for fractures and foreign bodies should be done when feasible. The wound should be irrigated through a 19-gauge needle with $150 \mathrm{~mL}$ or more of sterile normal saline or lactated Ringer's solution. Devitalized tissues should be débrided. Drainage of the wound, when indicated, can be performed in customary fashion or by using gentle suction with a 19-gauge scalp vein tubing connected to a vacuum blood-collecting tube [45]. A controversy still exists regarding whether or not bite wounds that are clinically uninfected and are seen within 24 hours should be surgically closed [23,28]. Margins of puncture wounds should be excised and left open after irrigation. Margins of other wounds should be excised and primary closure carried out, with or without drainage $[46 \bullet \bullet]$. The utility of suturing fresh bite wounds less than 6 hours after the injury is undetermined, except for facial wounds. Delayed primary closure or edge approximation should be done in wounds associated with crush injury, preexisting edema, and injuries to the hands or feet.

In caring for a bite by a monkey that may be a B-virus carrier, the wound should be thoroughly scrubbed with soap or detergent and irrigated for at least 15 minutes, and viral cultures should be performed after cleansing [43]. Serum for B-virus-specific acute viral serology should be stored at $-20^{\circ} \mathrm{C}$, and compared with a second sample obtained 21 days later. Antiviral therapy with acyclovir, valacyclovir, or famciclovir should be given to those with moderate or high-risk wounds [25].
Bites of the hand are at the highest risk of deep damage and severe infection because sharp teeth may penetrate tendon sheaths or the midpalmar space. Human bites should be treated by widely opening the wound, débriding, and irrigating thoroughly; primary closure and tendon and nerve repair should be delayed [47]. Following débridement and irrigation, dog bites can be considered clean, and primary closure can be performed. Hospitalization may be necessary in severe cases, with immobilization by splinting or bulky dressings and elevation.

Facial bites, especially of children, require meticulous management. Nearly all victims do well with careful débridement, ample irrigation and cleansing, and loose closure by suture. Close follow-up for at least 5 days is required. Subsequent plastic reconstruction may be needed, and consultation with a plastic surgeon at the time of initial repair may be useful.

Early management of all human bites, especially those to the hand, must be thorough and vigorous. Clenched-fist injuries require more intensive care, preferably by a hand surgeon, to evaluate the seriousness of injury to the tendon, sheath, joint capsule, joint, and bone.

Rabies prevention should be given after dog bites that indicate such measures [48]. This includes hyperimmune serum and active immunization. A tetanus toxoid booster should be administered if the patient has been adequately immunized before and has received the most recent dose within the past 10 years. Tetanus immune globulin (human) is required if tetanus immunization has not taken place or is inadequate.

The infectious complications of dog bites make the concept of prophylactic antibiotics attractive. Using antibiotics may be helpful, particularly in high-risk wounds such as those of the hand. The choice of a particular antibiotic for prophylaxis and/or treatment must be based on bacteriology. Unfortunately, no single antibiotic can be expected to effectively treat infections caused by all the organisms that can be present in an infected bite.

The role of prophylactic antimicrobial therapy in bite wounds presenting early is uncertain $[43,45]$. However, because these wounds are usually contaminated with potential pathogens, preemptively treating all patients having deep bite wounds with antibiotics is advisable. These include puncture wounds, facial bites, and any wound over a tendon or bone.

Antimicrobial treatment should be administered for all bite wounds, with the exception of patients who present 72 hours or more after injury and have no clinical signs of infection. Antimicrobial therapy of bite wounds is not usually prophylactic, but rather a therapeutic intervention.

Because no single antimicrobial reliably eradicates all of the major pathogens responsible for bite wound infections, establishing a specific etiologic diagnosis by 


\begin{tabular}{lcc}
\hline $\begin{array}{l}\text { Table 2. Antimicrobials effective in the empiric } \\
\text { treatment of patients with animal bite and } \\
\text { human bite wounds }\end{array}$ & Animal bite & Human bite \\
\hline & + & + \\
Amoxicillin-clavulanate (PO) & + & + \\
Ampicillin-sulbactam (IV) & + & + \\
Cefoxitin (IV) & + & + \\
Moxifloxacin (PO, IV) & + & + \\
Gatifloxacin (PO, IV) & + & + \\
Doxycycline (PO, IV) & & \\
IV-intravenously; PO-orally. & &
\end{tabular}

obtaining cultures is helpful in guiding therapy (Table 2) [49]. Penicillin or ampicillin are the most active agents against $P$. multocida and the other oral flora. However, $S$. aureus and almost half of the anaerobic gram-negative bacilli recovered in human bite wounds are resistant to these drugs [50]. The isolation of $\beta$-lactamase-producing organisms from more than $40 \%$ of bite wounds excludes the use of penicillins for bite infections [11]. Although oxacillin is effective against $S$. aureus, it has poor activity against many bite isolates; $18 \%$ of $P$. multocida, $24 \%$ of Bacteroides spp, and more than $50 \%$ of other aerobic gram-negative strains were resistant to oxacillin [50]. Doxycycline is a good alternative but should not be used in children younger than 8 years of age. When $S$. aureus is suspected (based on the gram stain of aspirate, which is specific but not sensitive), penicillin (to cover streptococci) and a penicillinase-resistant penicillin should be used. If methicillin-resistant $S$. aureus (MRSA) is recovered, vancomycin, linezolid, or other MRSA-effective antimicrobial should be administered. The combination of amoxicillin and clavulanic acid has been effective in the therapy of human bites and dog bites [49,51]. This combination has a wide spectrum of activity against most pathogens isolated from these wounds. First-generation cephalosporins are not as effective as the combination of amoxicillin and clavulanic acid because of the resistance of some anaerobic bacteria and E. corrodens. Clindamycin and the penicillinase-resistant penicillins should not be administered without penicillin because of their poorer activity against $P$. multocida. Erythromycin is generally ineffective against $P$. multocida, Moraxella spp, fusobacteria, and peptostreptococci. Azithromycin is generally more active than clarithromycin against all Pasteurella spp. Azithromycin and clarithromycin are only modestly effective against E. corrodens and peptostreptococci. Cefoxitin or the combination of penicillin or a firstgeneration cephalosporin plus a $\beta$-lactamase-resistant penicillin or the combination of ticarcillin and clavulanic acid will provide adequate parenteral therapy for animal and human bites. The newer quinolones (gatifloxacin and moxifloxacin) are active against all major bite wound pathogens, including anaerobic bacteria [52]. However, these agents are not approved for use in children.
E. corrodens, a capnophilic Gram-negative rod that is part of the normal oral flora, can be recovered from $25 \%$ of human bite wounds [21]. E. corrodens is susceptible to penicillin, ampicillin, and the quinolones but resistant to oxacillin, methicillin, nafcillin, and clindamycin, and some strains are resistant to cephalosporins [49,50,52]. Therefore, any isolated E. corrodens should undergo susceptibility testing if cephalosporin therapy is considered.

When antibiotics are administered in this manner and are combined with good wound toilet, most bite wounds can be sutured with good results and an acceptable infection rate. The duration and route of antibiotic therapy should be individualized based on the site involved, the culture results, and the response to treatment. A 7- to 14-day course is generally adequate for infections limited to soft tissue, and a minimum of 21 days of therapy is generally required for infections involving joints or bones.

\section{Complications}

Complications are common in hand wounds, with $30 \%$ or more becoming infected [45]. The rate of complications is high because of the presence of avascular tendon and sheath spaces and the propensity of the infection to spread. These infections may have disastrous consequences on function. In addition to local wound infection, other complications include lymphangitis, local abscess, septic arthritis, tenosynovitis, and osteomyelitis [22,43]. Rare complications include endocarditis, meningitis [53], brain abscess [54], and sepsis with disseminated intravascular coagulation [55], especially in immunocompromised individuals. Especially prone to complications are individuals receiving systemic corticosteroids and patients with lupus erythematosus or acute leukemia.

\section{Transmission of other infections}

Cat scratches and cat bites, as well as flea bites, can transmit the cat scratch-disease agent Bartonella (formerly Rochalimaea) henselae [56].

Tetanus can result from animal and human bites [57]. The patient's tetanus immunization status must be determined after bite wounds that penetrate the skin. Tetanus toxoid and/or tetanus immune globulin should be given when required or if doubt exists about the timing or previous receipt of tetanus immunization [57].

Bites, abrasions, scratches, or exposure to animal saliva through mucous membranes or a break in the skin all can transmit rabies. The possibility of rabies exposure should always be considered after most animal bites, especially for unprovoked attacks or if the animal seems ill or was a stray. Postexposure prophylaxis can prevent unnecessary deaths and should be administered when indicated [58].

Human bites can transmit other infections. These include hepatitis viruses $\mathrm{B}(\mathrm{HBV})$ and $\mathrm{C}$, primary syphilis, and herpes simplex virus [58]. Because the risk for transmitting HIV through saliva is very low, postexposure prophylaxis is not recommended $[59,60]$. 
Patients negative for anti-hepatitis B surface antibodies who were bitten by an individual positive for hepatitis B surface antigen should receive both hepatitis B immune globulin and hepatitis $B$ vaccine. Individuals working in institutions where the risk for human bites is high should receive the $\mathrm{HBV}$ vaccination at the start of employment.

\section{Conclusions}

Animal and human bite wounds can lead to serious infection and complications. The organisms that can be isolated from bite wounds generally represent the oral cavity of the biting animal and the victim's skin flora. When proper techniques are used, anaerobic bacteria can be isolated from more than two thirds of human and animal bite wound infections, especially those associated with abscess formation. Management of bite wound infections includes administering proper local therapy and using appropriate antimicrobial agents when needed.

\section{Disclosure}

No potential conflict of interest relevant to this article was reported.

\section{References and Recommended Reading}

Papers of particular interest, published recently, have been highlighted as:

\section{- Of importance \\ $\bullet \quad$ Of major importance}

1. McCaig LF: National Hospital Ambulatory Medical Care Survey: 1998 emergency department summary. Adv Data 2000, 313:1-23.

2. Talan DA, Abrahamian FM, Moran GJ, et al.: Emergency Medicine Human Bite Infection Study Group: Clinical presentation and bacteriologic analysis of infected human bites in patients presenting to emergency departments. Clin Infect Dis 2003, 37:1481-1489.

3. Litovitz TL, Klein-Schwartz W, White S, et al.: 2000 Annual report of the American Association of Poison Control Centers Toxic Exposure Surveillance System. Am J Emerg Med 2001, 19:337-395.

4.• Daniels DM, Ritzi RB, O’Neil J, Scherer LR: Analysis of nonfatal dog bites in children. J Trauma 2009, 66(3 Suppl): S17-S22.

This study examined the hospital incidence, costs, and characteristics of dog bite injuries among children by age group and hospitalization. During 8 years, 1347 children younger than 18 years were treated for dog bites (1.5\% of all pediatric injuries). Most were treated and released from the emergency department $(91 \%)$. Of the 66 children $(4.9 \%)$ requiring inpatient admission, the median length of stay was 2 days. Victims were frequently male $(56.9 \%)$ and younger than 8 years $(55.2 \%)$. Children younger than 5 years represented $34 \%$ of all dog bite victims but $50 \%$ of all children requiring hospitalization. The cost of direct medical care during the study was $\$ 2.15$ million.

5. Mann RJ, Hoffeld TA, Farmer CB: Human bites of the hand: twenty years of experience. J Hand Surg 1977, 2:97-104.

6. Goldstein EJC: New horizons in the bacteriology, antimicrobial susceptibility and therapy of animal bite wounds. J Med Microbiol 1998, 47:95-97.
7. Goldstein EJC, Citron DM, Finegold SM: Role of anaerobic bacteria in bite wound infections. Rev Infect Dis 1984 , 6(Suppl 1):177-183.

8. Alexander CJ, Citron DM, Gerardo SH, et al.: Characterization of saccharolytic Bacteroides and Prevotella isolates from infected dog and cat bite wounds in humans. J Clin Microbiol 1997, 35:406-411.

9. Citron DM, Hunt Gerardo S, Claros MC, et al.: Frequency of isolation of Porphyromonas species from infected dog and cat bite wounds in humans and their characterization by biochemical tests and arbitrarily primed-polymerase chain reaction fingerprinting. Clin Infect Dis 1996, 23(Suppl 1):78-82.

10. Holst E, Rollof J, Larsson L, Nielsen JP: Characterization and distribution of Pasteurella species recovered from infected humans. J Clin Microbiol 1992, 30:2984-2987.

11. Brenner DJ, Hollis DG, Fanning GR, Weaver RE: Capnocytophaga canimorsus sp nov (formerly CDC group DF-2), a cause of septicemia following dog bite, and C. cynodegmi sp nov, a cause of localized wound infection following dog bite. J Clin Microbiol 1989, 27:231-235.

10. Andersen BM, Steigerwalt AG, O'Connor SP, et al.: Neisseria weaveri sp nov, formerly CDC group M-5, a gram-negative bacterium associated with dog bite wounds. J Clin Microbiol 1993, 31:2456-2466.

11. Reina J, Borrell N: Leg abscess caused by Weeksella zoohelcum following a dog bite. Clin Infect Dis 1992, 14:1162-1163.

12. Guidourdenche M, Lambert T, Riou JY: Isolation of Neisseria canis in mixed culture from a patient after a cat bite. J Clin Microbiol 1989, 27:1673-1674.

13. Talan DA, Goldstein EJC, Staatz D, Overturf GD: Staphylococcus intermedius: clinical presentation of a new human dog bite pathogen. Ann Emerg Med 1989, 18:410-413.

14. Hollis DG, Moss CW, Daneshvar MI, et al.: Characterization of Centers for Disease Control group NO-1, a fastidious, nonoxidative, gram-negative organism associated with dog and cat bites. J Clin Microbiol 1993, 31:746-748.

15. Moss CW, Wallace PL, Hollis DG, Weaver RE: Cultural and chemical characterization of CDC groups EO-2, M-5 and M-6, Moraxella (Moraxella) species, Oligella urethralis, Acinetobacter species, and Psychrobacter immobilis. J Clin Microbiol 1988, 26:484-492.

16. Goldstein EJC, Citron DM, Merkin TE, Pickett MJ: Recovery of an unusual Flavobacterium group IIb-like isolate from a hand infection following pig bite. J Clin Microbiol 1990, 28:1079-1081, 1990.

17. Peel MM, Hornidge KA, Luppino M, et al.: Actinobacillus spp and related bacteria in infected wounds of humans bitten by horses and sheep. J Clin Microbiol 1991, 29:2535-2538.

18. Murphey DK, Septimus EJ, Waagner DC: Catfish-related injury and infection: report of two cases and review of the literature. Clin Infect Dis 1992, 14:689-693.

19. Capellan J, Fong IW: Tularemia from a cat bite: case report and review of feline-associated tularemia. Clin Infect Dis 1993, 16:472-475.

20. Guba AM, Mulliken JB, Hoopes JE: The selection of antibiotics for human bites of the hand. Plast Reconstr Surg 56:538-41, 1975.

21. Goldstein JC, Citron DM Wield B, et al.: Bacteriology of human and animal bite wounds. J Clin Microbiol 1978, 8:667-672.

22. Brook I: Microbiology of human and animal bite wounds in children. J Pediatr Infect Dis 1987, 6:29-32.

23. Goldstein EJC, Citron DM, Finegold SM: Dog bite wounds and infection: a prospective clinical study. Ann Emerg Med 1980, 9:508-512.

24. Talan DA, Citron DM, Abrahamian FM, et al.: Bacteriologic analysis of infected dog and cat bites. Emergency Medicine Animal Bite Infection Study Group. N Engl J Med 1999, 340:85-92. 
25. Holmes GP, Chapman LE, Stewart J, et al.; B Virus Working Group: Guidelines for the prevention and treatment of B virus infections in exposed persons. Clin Infect Dis 1995, 20:421-439.

26. Peel NM, Hornridge KA, Luppino M, et al.: Actinobacillus spp and related bacteria in infected wounds of humans bitten by horses and sheep. J Clin Microbiol 1991, 29:2535-2538.

27. Bailey GD, Moore LVH, Love DN, Johnson JL: Bacteroides heparinolytica: deoxyribonucleic acid relatedness of strains from the oral cavity and oral-associated disease conditions of horses, cats, and humans. Int J System Bacteriol 1988, $38: 42-44$.

28. Barnham M: Pig bite injuries and infection: report of seven human cases. Epidemiol Infect 1988, 101:641-645.

29. Rolle U: Haemophilus influenzae cellulitis after bite injuries in children. I Pediatr Surg 2000, 35:1408-1409.

30. Morgan MS: Treatment of pig bites. Lancet 1996, 348:1246.

31. Auerbach PS, Yajko DM, Nassos PS, et al.: Bacteriology of the marine environment: implications for clinical therapy. Ann Emerg Med 1987, 16:643-649.

32. Pavia AT, Bryan JA, Maher KL, et al.: Vibrio carchariae infections after a shark bite. Ann Intern Med 1989, 111:85-86.

33. Buck JD, Spotte S, Gadbaw JJ Jr: Bacteriology of the teeth from a great white shark: potential medical implications for shark bite victims. J Clin Microbiol 1984, 849-851.

34. Rosenthal SG, Bernhardt HE, Phillips JA 3rd: Aeromonas hydrophila wound infections. Plast Reconstr Surg 1974, 53:77-79.

35. Revord ME, Goldfarb J, Shurin SB: Aeromonas hydrophila wound infection in a patient with cyclic neutropenia following a piranha bite. Pediatr Infect Dis J 1988, 7:70-71.

36. Flandry F, Lisecki EJ, Domingue GJ, et al.: Initial antibiotic therapy for alligator bites. South Med J 1989, 82:262-266.

37. Murphey DK, Septimus EJ, Waagner DC: Catfish-related injury and infection: report of two cases and review of the literature. Clin Infect Dis 1992, 14:689-693.

38. Berkowitz FE, Jacobs DWC: Fatal case of brain abscess caused by rooster pecking. Pediatr Infect Dis J 1987, 6:941-942.

39. Davis B, Wenzel RP: Striges scalp: Bacteroides infection after an owl attack. J Infect Dis 1992, 165:975-976.

40. Eberly RJ, Hayek LJ: Antibiotic prophylaxis after a swan bite. Lancet 1997, 350:340.

41. Paisley JW, Lauer BA: Severe facial injuries to infants due to unprovoked attacks by pet ferrets. JAMA 1988, 259:2005-2006.

42. Kalb R, Kaplan MH, Tenenbaum MJ, et al.: Cutaneous infection at dog bite wounds associated with fulminant DF-2 septicemia. Am J Med 1985, 78:687-690.

43. Szalay GC, Sommerstein A: Inoculation osteomyelitis secondary to animal bites. Clin Pediatr 1972, 11:687-689.

44. Galvin JR, DeSimone D: Infection rate of simple suturing. JACEP 1976, 5:332-333.
45. Graham WP III, Calabretta AM, Miller SH: Dog bites. Am Fam Physician 1977, 15:132-137.

46.• Stefanopoulos PK: Management of facial bite wounds. Oral Maxillofac Surg Clin North Am 2009, 21:247-257.

This review outlines the treatment of facial bites, which are especially prone to infectious complications, both local and systemic. Beyond the initial tissue damage, complications can create difficulties for restoring an esthetic appearance. Management should aim to neutralize the potential for infection and provide an infectionfree environment for wound healing. Wound cleansing followed by primary closure is the treatment of choice, and use of prophylactic antibiotics may further decrease the infection risk.

47. Nardi GL, Zuidema GD, eds: Surgery: A Concise Guide to Clinical Practice, edn 3. Boston: Little, Brown; 1972.

48. Manning SE, Rupprecht CE, Fishbein D, et al.: Human rabies prevention-United States, 2008: recommendations of the Advisory Committee on Immunization Practices. MMWR Recomm Rep 2008, 57(RR-3):1-28.

49. Goldstein EJ: Selected nonsurgical anaerobic infections: therapeutic choices and the effective armamentarium. Clin Infect Dis 1994, 18(Suppl 4):S273-S279.

50. Goldstein EJC, Citron DM, Vagvolgyi AE, Finegold SM: Susceptibility of bite wound bacteria to seven oral antimicrobial agents including RU-285, a new erythromycin: consideration for choosing empiric therapy. Antimicrob Agents Chemother 1986, 29:556-559.

51. Goldstein EJ, Citron DM: Comparative activities of cefuroxime, amoxicillin-clavulanic acid, ciprofloxacin, enoxacin, and ofloxacin against aerobic and anaerobic bacteria isolated from bite wounds. Antimicrob Agents Chemother 1988, 32:1143-1148.

52. Goldstein EJ, Citron DM, Merriam CV, et al.: Activity of gatifloxacin compared to those of five other quinolones versus aerobic and anaerobic isolates from skin and soft tissue samples of human and animal bite wound infections. Antimicrob Agents Chemother 1999, 43:1475-1479.

53. Bracis R, Seibers K, Jullien RM: Meningitis caused by group II J following a dog bite. West J Med 1979, 131:438-440.

54. Klein DM, Cohen ME: Pasteurella multocida brain abscess following perforating cranial dog bite. J Pediatr 1978, 92:588-589.

55. Check W: An odd link between dog bites, splenectomy. JAMA 1979, 241:225-226.

56. Florin TA, Zaoutis TE, Zaoutis LB: Beyond cat scratch disease: widening spectrum of Bartonella henselae infection. Pediatrics 2008, 121:e1413-e1425.

57. Brook I: Current concepts in the management of Clostridium tetani infection. Expert Rev Anti Infect Ther 2008, 6:327-336.

58. Jackson AC: Rabies. Neurol Clin 2008, 26:717-726.

59. Richman KM, Rickman LS: The potential for transmission of human immunodeficiency virus through human bites. J Acquir Immune Defic Syndr 1993, 6:402-406.

60. Havens PL: Postexposure prophylaxis in children and adolescents for nonoccupational exposure to human immunodeficiency virus. Pediatrics 2003, 111:1475-1489. 